\title{
Polynuclear Nickel Hexacyanoferrate/Graphitized Mesoporous Carbon Hybrid Chemically Modified Electrode for Selective Hydrazine Detection
}

\author{
Palani Barathi, ${ }^{1}$ Annamalai Senthil Kumar, ${ }^{1}$ and Minnal Ranjan Babu Karthick ${ }^{2}$ \\ ${ }^{1}$ Environmental and Analytical Chemistry Division, School of Advanced Sciences, Vellore Institute of Technology, \\ Vellore 632 014, India \\ ${ }^{2}$ Sensor Systems Technology Division, School of Electronics and Engineering, Vellore Institute of Technology, Vellore 632 014, India
}

Correspondence should be addressed to Annamalai Senthil Kumar, askumarchem@yahoo.com

Received 17 May 2011; Revised 20 July 2011; Accepted 3 August 2011

Academic Editor: Aleksandar Radu

Copyright ( $) 2011$ Palani Barathi et al. This is an open access article distributed under the Creative Commons Attribution License, which permits unrestricted use, distribution, and reproduction in any medium, provided the original work is properly cited.

\begin{abstract}
A hybrid polynuclear nickel hexacyanoferrate (NiHCFe)/graphitized mesoporous carbon- (GMC-) modified glassy carbon electrode (GCE/NiHCFe@GMC) has been prepared by a sequential method using electrodeposited Ni on a GMC-modified glassy carbon electrode (GCE/Ni@GMC) as a template and $\left[\mathrm{Fe}(\mathrm{CN})_{6}\right]^{3-}$ as an in-situ chemical precipitant, without any additional interlinking agent. Physicochemical and electrochemical characterizations reveal the presence of NiHCFe units within the porous sites of the GMC. The GCE/NiHCFe@GMC electrode showed highly stable and well-defined redox behaviors with surface-confined electron-transfer mechanism in a pH 7 phosphate buffer solution. The GCE/NiHCFe@GMC showed about 20 times enhancement in hydrazine oxidation peak current along with $500 \mathrm{mV}$ reduction in overpotential over the corresponding unmodified GCE/GMC. Hydrazine calibration plots by $\mathrm{CV}$ and amperometric $i$ - $t$ methods were linear up to $1 \mathrm{mM}$ and $220 \mu \mathrm{M}$ with current sensitivity values of $15.86 \mu \mathrm{A} / \mathrm{mM}$ and $7.37 \mathrm{nA} / \mu \mathrm{M}$, respectively. Calculated detection limit by the amperometric $i-t$ method was $23.2 \mathrm{nM}$. The hybrid GCE/NiHCFe@GMC exhibits remarkable tolerance to important industrial and biological interferents. Finally determination of hydrazine in cigarette smoke sample was successfully demonstrated.
\end{abstract}

\section{Introduction}

Hydrazine is a toxic and carcinogenetic chemical used for several industrial, environmental, and aerospace applications (as a fuel). A burning cigarette produces hundreds of gaseous and particulate compounds including hydrazine (31.4 ng/ cigarette) in the smoke formed by pyrolysis or combustion of tobacco $[1,2]$. Sufficient information is available on the carcinogenic effects of hydrazine and its derivatives in experimental animals $[1,2]$. Hydrazine is used in agricultural, chemical blowing agents, pharmaceutical intermediates, photography chemicals, boiler water treatment for corrosion protection, and as a fuel for rockets and space craft [3-6]. Hydrazine itself or its sulphate salt has been used in the treatment of tuberculosis, sickle cell anemia, and some of the chronic illnesses $[7,8]$. Thus, sensitive and selective detection of hydrazine in real samples is of significant research interest in analytical chemistry. For hydrazine real-sample analysis, various spectroscopic and chromatographic methods especially derivatization approach, where hydrazine reacted with pentafluorobenzaldehyde to form corresponding decafluorobenzaldehyde azine [9], have been reported. The conventional assays require tedious sample preparation and time-consuming instrumental procedures $[9,10]$. Meanwhile, some electroanalytical techniques were also adopted for the quantitative determination of hydrazine real-sample analyses. For example, copper-palladium alloy nanoparticle plated electrode and barrel plated rhodium nail electrode for the determination of hydrazine in tobacco and water samples, respectively $[11,12]$. Note that the electroanalytical techniques have several advantages over the conventional spectroscopic methods which include portability of the working instrument, less sample preparation duration, direct measurements and extendibility to disposable type screen- 
printed electrodes systems and so forth. In this work, we are reporting a polynuclear nickel hexacyano-ferrate (NiHCFe)/ graphitized mesoporous carbon- (GMC-) modified glassy carbon electrode (designated as GCE/NiHCFe@GMC, GCE: glassy carbon electrode) prepared by cathodically deposited Ni on GMC-modified GCE as a template (GCE/Ni@GMC) and $\left[\mathrm{Fe}(\mathrm{CN})_{6}\right]^{3-}$ as a precipitant for stable and physiological solution ( $\mathrm{pH} 7$ sodium phosphate buffer solution, PBS) operable electro-catalytic oxidation of hydrazine.

As an important class of fairly well-defined zeolite-like polynuclear inorganic mixed-valence compounds, transition metal hexacyanoferrate (MHCNFe, $\mathrm{M}=\mathrm{Fe}, \mathrm{Ni}, \mathrm{Co}$, and $\mathrm{Ru}$ ) also referred as Prussian blue analogues have received wide research interest because of their interesting electrochemical properties [13-17]. Among the Prussian blue analogues, polynuclear nickel hexacyanoferrate $\left(-\mathrm{Ni}^{\mathrm{II}}-\mathrm{NC}-\mathrm{Fe}^{\mathrm{III} / \mathrm{II}}-\mathrm{CN}-\right.$ $\mathrm{Ni}^{\mathrm{II}}$ - net work; NiHCFe) has gained special attention due to its well-defined single reversible redox peak in the presence of alkali metal ion solution [16, 18-20]. Few papers reported ex situ deposited NiHCFe/CNT hybrid units, where a mixture containing $\mathrm{Ni}^{2+}$ and $\mathrm{Fe}(\mathrm{CN})_{6}{ }^{3-}$ was first converted to NiHCFe complex particles, and then they were allowed to assemble/adsorb on the CNT [21-26]. Recently our group found out a new in situ route for stable immobilization of $\mathrm{NiHCFe}$ on a functionalized multiwalled carbon nanotube modified GCE (GCE/NiHCFe@f-MWCNT, f: functionalized) and for selective hydrazine electrocatalytic oxidation [27]. However, in consideration with cost, purification, functionalization, and complication with the metal ion impurities, the CNTs will not be a good choice as a matrix for hybrid electrode formation. Alternately, in this work, we are introducing a low-cost and metal ion impurity-free carbon material, graphitized mesoporous carbon (GMC) as a matrix to immobilize NiHCFe and for efficient electrocatalytic oxidation of the hydrazine in a physiological solution. Finally, a cigarette smoke real-sample analysis was demonstrated with the above electrode.

\section{Experimental Section}

2.1. Reagents and Materials. Graphitized mesoporous carbon (>99\% purity) was purchased from Aldrich, nickel chloride hexahydrate $\left(\mathrm{NiCl}_{2} \cdot 6 \mathrm{H}_{2} \mathrm{O}\right)$ was obtained from Central drug house (P) Ltd, potassium ferricyanide from Merck, and hydrazine sulphate extra pure from Sisco's Research Laboratories, India. Other chemicals were of analytical grade and used as received without further purification. Aqueous solutions were prepared using deionized and alkaline $\mathrm{KMnO}_{4}$ distilled water (designated as DD water). Unless otherwise stated, a $\mathrm{pH} 7$ phosphate buffer solution (PBS) of ionic strength $0.1 \mathrm{M}$ was used as a supporting electrolyte in this study.

2.2. Apparatus. Voltammetric measurements were carried out using CHI model 660C electrochemical work station, USA with $10 \mathrm{~mL}$ working volume. The three-electrode system consisted of glassy carbon electrode (GCE) of $0.0707 \mathrm{~cm}^{2}$ geometrical surface area and its chemically modified form (CME) as a working electrode, $\mathrm{Ag} / \mathrm{AgCl}$ with $3 \mathrm{M} \mathrm{KCl}$ as a reference electrode, and platinum wire as a counter electrode. Bioanalytical system (BAS, USA) polishing kit was used to polish the GCE surface. The surface of the GCE was cleaned first mechanically by polishing with 500 micron alumina powder, washing with DD water, and sonicating for $5 \mathrm{~min}$. The electrochemical pretreatment procedure consisted of potential cycling of the above electrode in a potential window from 0 to $0.9 \mathrm{~V}$ versus $\mathrm{Ag} / \mathrm{AgCl}$ continuously for 10 cycles $(n=10)$ at a potential scan rate $(v)$ of $50 \mathrm{mV} \mathrm{s}^{-1}$ in a $\mathrm{pH} 7 \mathrm{PBS}$.

2.3. Procedures. A GMC stock solution was first prepared as a suspension by mixing $1 \mathrm{mg}$ of the GMC in $500 \mu \mathrm{L}$ ethanol. Prior to the surface coating, the stock solution was sonicated for 3-5 min, and $5 \mu \mathrm{L}$ of the suspension was drop-coated on the pretreated GCE (designated as GCE/GMC). It was allowed for $\sim 3$ minutes in air for complete drying. The modified electrode was electrochemically pretreated for twenty continuous cycles $(n=20)$. There was no sign of any faradaic electron-transfer behavior with the GCE/GMC. All experiments were performed with normal dissolved oxygen (DO) that closely resembles the physiological system.

Scheme 1 illustrates preparation of the GCE/NiHCFe@ GMC by a template-assisted procedure in two steps. Step 1 consists of preparation of GCE/Ni@GMC, where $\mathrm{Ni}^{2+}$ was cathodically deposited on the GCE/GMC from a solution containing $6 \mathrm{mM} \mathrm{NiCl}_{2}$ in $0.1 \mathrm{M} \mathrm{pH} 7 \mathrm{PBS}$ at an applied potential $\left(E_{\text {app }}\right)$ of $-0.9 \mathrm{~V}$ versus $\mathrm{Ag} / \mathrm{AgCl}$ for $180 \mathrm{~s}$ (optimal). The GCE/Ni@GMC electrode was used as a template in Step 2 for the GCE/NiHCFe@GMC preparation. In this procedure, the template was subjected to potential cycling treatment in presence of $1 \mathrm{mM} \mathrm{K}_{3}\left[\mathrm{Fe}(\mathrm{CN})_{6}\right]$ in a potential window of 0 to $0.9 \mathrm{~V}$ versus $\mathrm{Ag} / \mathrm{AgCl}$ with a scan rate of $50 \mathrm{mV} / \mathrm{s}$ $(n=20)$. This procedure allows the in situ formation of $\mathrm{NiHCFe}$ units, where the $\mathrm{Ni}$ active sites are formed, within the GMC (Scheme 1(c)). The modified electrode is referred as GCE/NiHCFe@GMC. After preparation, the electrode was washed with DD water and conditioned by CV potential cycling again in the potential range of $0 \mathrm{~V}$ to $0.9 \mathrm{~V}$ for 20 times in a blank $\mathrm{pH} 7 \mathrm{PBS}$ at $v=50 \mathrm{mV} \mathrm{s}^{-1}$. Control NiHCFemodified GCE was also prepared (GCE/NiHCFe) in a similar way as mentioned above without any GMC coating on the GCE.

For the case of scanning electron microscopy (SEM) characterization (HITACHI SU 6600, Japan), NiHCFe@ GMC particles scratched out from the GCE/NiHCFe@GMC system were taken for the analyses.

2.4. Real-Sample Analysis. A branded cigarette pack was purchased from local shop and used without any pre-treatment. The cigarette smoke was collected in $0.1 \mathrm{M}$ pH $7 \mathrm{PBS}\left(\mathrm{N}_{2}\right.$ purged) using a dreschel's bottle. In that procedure, burning cigarette (four numbers successively) was first placed on one end of the glass tube of the dreschel's bottle which is immersed in $150 \mathrm{~mL} \mathrm{pH} 7 \mathrm{PBS}$. The other glass tube was connected to a suction pump, which was used to suck the smoke into the bottle. The cigarette smoke gases were 


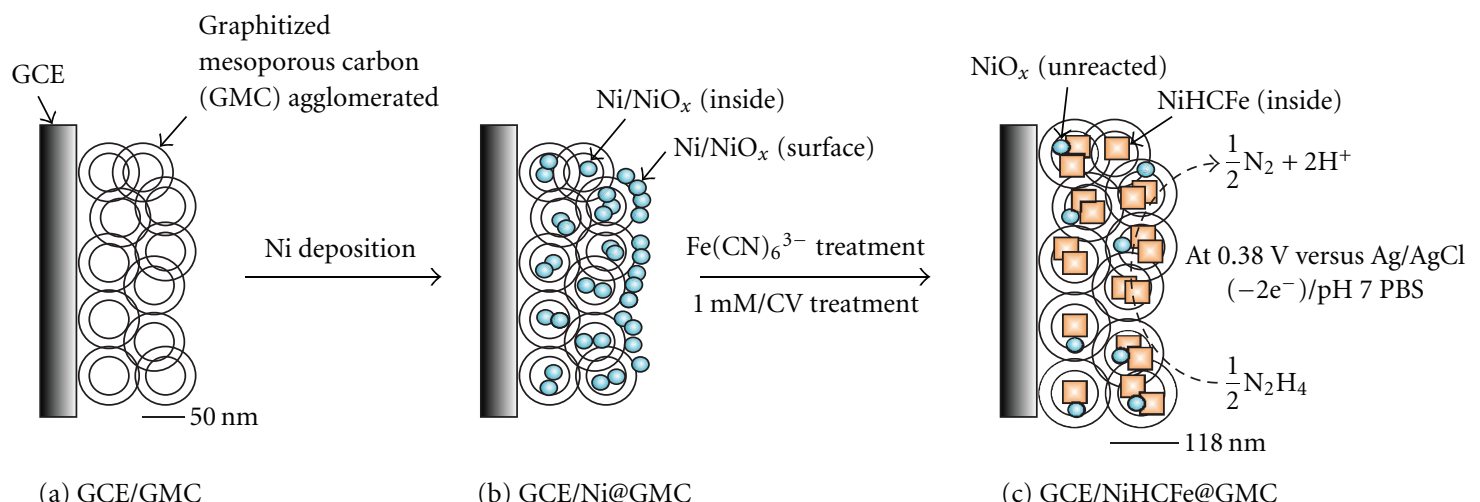

(a) GCE/GMC

(b) GCE/Ni@GMC

(c) GCE/NiHCFe@GMC

SCHEME 1: Illustration for the in situ precipitation of NiHCFe units within GMC by a sequential preparation method.

bubbled through the $150 \mathrm{~mL}$ PBS. The smoke gas-dissolved solution was taken as a test sample for electro-analysis. $100 \mu \mathrm{L}$ of the real-sample aliquots was spiked into $10 \mathrm{~mL}$ of the working cell for the real-sample analysis. For the hydrazine quantification assay, standard addition method was adopted.

\section{Results and Discussions}

3.1. SEM Characterization of the NiHCFe@GMC. Figure 1 shows typical SEM images of GMC (a) and NiHCFe@GMC (b) and (c). The GMC shows agglomerated clusters of several individual particles of size about $50 \mathrm{~nm}$. After the NiHCFe active site modification on the GMC, an average particle size of $118 \mathrm{~nm}$ was noticed, and this size is 2.3 times higher than the respective unmodified GMC. Energy dispersive analysis (EDX) of the NiHCFe@GMC shows presence of the following metals with its atomic \% percentage values of $\mathrm{C}$ (89.26), $\mathrm{N}$ (0.89), O (9.39), $\mathrm{Na}(0.40), \mathrm{Cl}(0.17), \mathrm{Fe}(0.18)$, and $\mathrm{Ni}$ (0.70) (figure not enclosed). It is surprising that there is no appearance of NiHCFe cubes on the surface of the NiHCFe@ GMC materials in the SEM photographs (Figures 1(b) and 1(c)). Similar kind of observation with absence of any surface $\mathrm{NiHCFe}$ species was observed in our previous NiHCFe@fMWCNT system [27]. Possibly, the NiHCFe active sites were all formed inside the porous GMC and, hence, absence of the surface NiHCFe units in this work.

3.2. Electrochemical Characterization. Figure 2 shows the comparative CV responses of GCE/NiHCFe@GMC and GCE/NiHCFe-modified electrodes in a pH 7 PBS. The GCE/NiHCFe@GMC system showed a major well-defined reversible redox response $(\mathrm{A} 1 / \mathrm{C} 1)$ centered at $E^{o^{\prime}}$ and peakto-peak separation $\left(\Delta E_{p}\right)$ values of $335 \mathrm{mV}$ versus $\mathrm{Ag} / \mathrm{AgCl}$ and $55 \mathrm{mV}$, respectively, along with a feeble postredox peak $\left(\mathrm{Al}^{\prime} / \mathrm{Cl}^{\prime}\right)$ correspondingly at $E^{o^{\prime}}=405 \mathrm{mV}$ versus $\mathrm{Ag} / \mathrm{AgCl}$ and $\Delta E_{p}=35 \mathrm{mV}$. This observation is closer to the Bácskai et al. report for a naked $\mathrm{NiHCFe-film-modified} \mathrm{gold} \mathrm{electrode}$ with a $E^{o^{\prime}}$ values of 400 and $500 \mathrm{mV}$ versus $\mathrm{Ag} / \mathrm{AgCl}$ in $0.5 \mathrm{M} \mathrm{K}_{2} \mathrm{SO}_{4}$ medium [14]. The two redox peaks appeared in the $\mathrm{CV}$ are due to the alkali metal ion-coupled electrontransfer reactions of various active sites as follows [14-17]:

$$
\begin{aligned}
& \mathrm{A} 1 / \mathrm{Cl}: \mathrm{NaNi}_{1.5}{ }^{\mathrm{II}}\left[\mathrm{Fe}^{\mathrm{II}}(\mathrm{CN})_{6}\right] @ \mathrm{GMC} \\
& \Longleftrightarrow \mathrm{Ni}_{1.5} \mathrm{II}\left[\mathrm{Fe}^{\mathrm{III}}(\mathrm{CN})_{6}\right] @ \mathrm{GMC}+\mathrm{e}^{-}+\mathrm{Na}^{+} \\
& \mathrm{Al}^{\prime} / \mathrm{Cl}^{\prime}: \mathrm{Na}_{2} \mathrm{Ni}^{\mathrm{II}}\left[\mathrm{Fe}^{\mathrm{II}}(\mathrm{CN})_{6}\right] @ \mathrm{GMC} \\
& \Longleftrightarrow \mathrm{NaNi}^{\mathrm{II}}\left[\mathrm{Fe}^{\mathrm{III}}(\mathrm{CN})_{6}\right] @ \mathrm{GMC}+\mathrm{e}^{-}+\mathrm{Na}^{+}
\end{aligned}
$$

In the above equations, $\mathrm{Na}_{2} \mathrm{Ni}^{\mathrm{iI}}\left[\mathrm{Fe}^{\mathrm{II}}(\mathrm{CN})_{6}\right]$ and $\mathrm{NaNi}_{1.5}{ }^{\mathrm{II}}\left[\mathrm{Fe}^{\mathrm{II}}(\mathrm{CN})_{6}\right]$ are referred to be stoichiometric and nonstoichiometric forms of the NiHCFe active sties, respectively. It was reported that the alkali metal ion intercalates with the stoichiometric form more stronger than the nonstoichiometric form [14]. As a result, the redox potentials of the $\mathrm{Na}_{2} \mathrm{Ni}^{\mathrm{II}}\left[\mathrm{Fe}^{\mathrm{II}}(\mathrm{CN})_{6}\right]$ appeared at $E^{o^{\prime}} \sim 400 \mathrm{mV}$ as an intense peak and $\mathrm{NaNi}_{1.5}{ }^{\mathrm{II}}\left[\mathrm{Fe}^{\mathrm{II}}(\mathrm{CN})_{6}\right]$ at $E^{o^{\prime}} \sim 500 \mathrm{mV}$ as a less intense peak [14]. But in the present case with the GCE/NiHCFe@GMC, a reverse in the trend was noticed, where the most intense redox peak appeared at less positive potential $\left(E^{o^{\prime}} \sim 335 \mathrm{mV}\right.$ ), and less intense peak was noticed at the most positive potential $\left(E^{o^{\prime}} \sim 405 \mathrm{mV}\right)$. In other words, the nonstoichiometric compound's redox reaction (1) showed more intense peak current than that of the stoichiometric reaction (2) in this work. It is expected that the NiHCFeimmobilized GMC has specific structure, which may markedly differ from the naked NiHCFe units as reported in the literature [14]. Possibly, as shown in the Scheme 1(c), $\mathrm{NiHCFe}$ units might be encapsulated within the porous structure of the GMC and, hence, some difficulty for the alkali metal intercalation reactions. This observation qualitatively resembles with the previous GCE/NiHCFe@f-MWCNT system [27], where the NiHCFe units were immobilized inside the $\mathrm{f}-\mathrm{MWCNT}$. Twenty continuous $\mathrm{CV}$ responses of GCE/NiHCFe@GMC at a sweep rate of $50 \mathrm{mV} / \mathrm{s}$ in pH 7 PBS resulted in a relative standard deviation (RSD) value for the anodic peak current, $i_{\mathrm{pa}}$, and peak potential, $E_{\mathrm{pa}}$, of 0.37 and $0.28 \%$, respectively. These low values denote appreciable stability of the modified electrode in a neutral $\mathrm{pH}$ unlike the conventional NiHCFe film with poor stability [23, 24, 27]. 


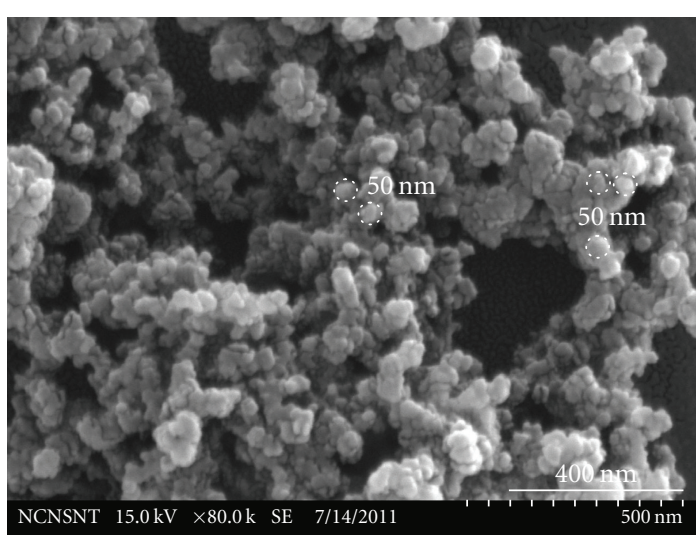

(a)

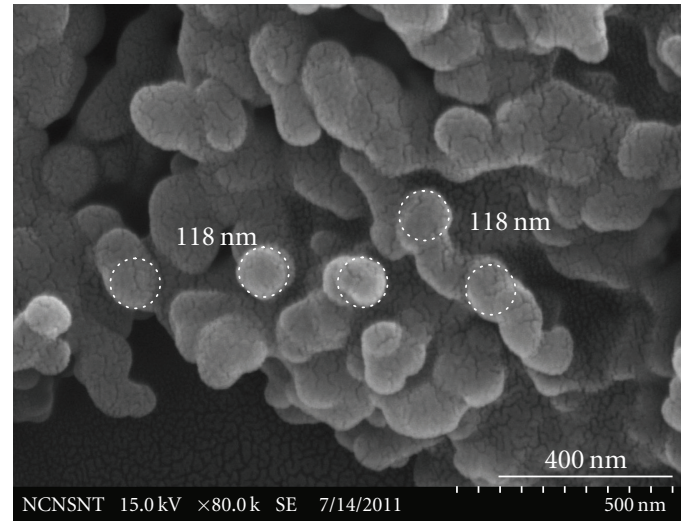

(b)

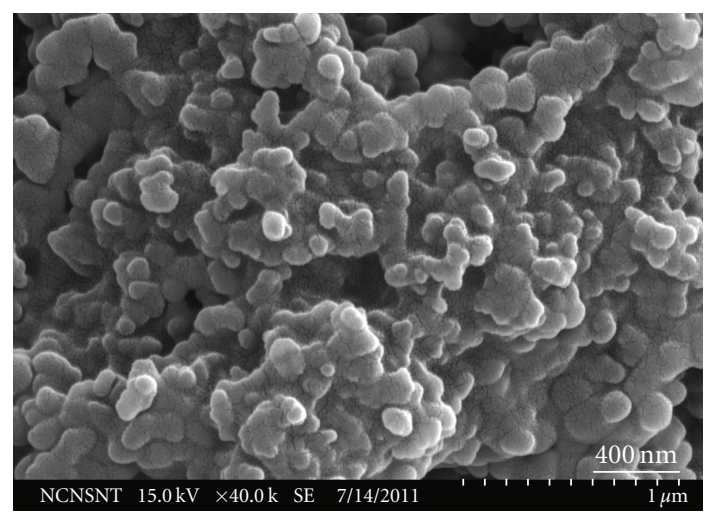

(c)

FIGURE 1: Typical SEM images of GMC (a) and NiHCFe@GMC (b) and (c).

The optimal preparation method adopted for the GMC/ NiHCFe@GMC case was extended to prepare GMC unmodified electrode, the GCE/NiHCFe as in Figure 2(B). Interestingly absence of any $\mathrm{NiHCFe}$ film formation on the GCE was noticed. Instability of the naked $\mathrm{NiHCFe}$ in neutral $\mathrm{pH}$ is the reason for the absence of the NiHCFe film on the GCE. These observations clearly indicate the significance of the GMC as a matrix for the NiHCFe immobilization and for stable physiological solution operation.

From the SEM/EDX measurements, atomic ratio calculated for the $\mathrm{Ni} / \mathrm{Fe}$ is 3.8, which is significantly higher over the ratio of 1 and 1.5 proposed earlier in the above equations. Presumably there will be some unreacted $\mathrm{Ni}$ as nickel oxide inside the GMC, which might be responsible for the higher ratio. Note that the nickel oxide $\left(\mathrm{NiO}_{x}, x=2\right)$ is reported not to be involved in the NiHCFe formation [27].

Effect of scan rate on the redox behavior of the GCE/ NiHCFe@GMC was further investigated as in Figure 3(a). A systematic increase in the redox peak currents was noticed upon increase of the voltammetric scan rate $(v)$. The ratio of cathodic-to-anodic peak currents $\left(i_{\mathrm{pc}} / i_{\mathrm{pa}}\right)$ at various scan rates is almost unity, and double logarithmic plots of $i_{\mathrm{pa}}$ and $i_{\mathrm{pc}}$ versus scan rate for $\mathrm{A} 1 / \mathrm{C} 1$ redox peak resulted in a slope value $\left(\partial \log \left(i_{p}\right) / \partial \log (v)\right)$ of 0.904 (Figure $\left.3(\mathrm{~b})\right)$. This number is closer to the ideal value of 1 for a surface-confined electron-transfer mechanism for a redox system [20].
Effect of solution $\mathrm{pH}$ on the redox behavior of the GCE/NiHCFe@GMC material was investigated as displayed in Figure 3(c). The peak potential values were independent of the solution $\mathrm{pH}$ over the range of 3-10 (Figure $3(\mathrm{~d})$ ), suggesting absence of any proton-coupled electron-transfer reaction with the hybrid matrix. This $\mathrm{pH}$-independent observation resembles with the GCE/NiHCFe@f-MWCNT system [27]. This experiment also evidence the good stability of the GCE/NiHCFe@GMC in the pH 3-10 without any fouling characteristic unlike the case of the physically adsorbed NiHCFe on graphite with marked dissolution of mediator at very high basic and acidic pHs [28].

Since alkali metal insertions play a key role in the redox reaction and for charge neutralization of the NiHCFe [29], effect of different alkali metal ions on the electrochemical behaviors of the GCE/NiHCFe@GMC was investigated by using CV. For the measurements, known amount of alkali metal ion was added with $\mathrm{pH} 7 \mathrm{PBS}$, and CV was run. Note that for unknown reasons the alkali metal ion-constituted in the PBS, was never utilized by the NiHCFe-modified electrode for the charge neutralization [27]. Figure 4(a) is the typical CV responses of GCE/NiHCFe@GMC in presence of added $0.1 \mathrm{M}$ of $\mathrm{Na}^{+}, \mathrm{Li}^{+}, \mathrm{K}^{+}, \mathrm{NH}_{4}^{+}$, and $\mathrm{Ba}^{2+}$ in a $\mathrm{pH}$ 7 PBS. The low ionic radii alkali metals, $\mathrm{Li}^{+}$and $\mathrm{Na}^{+}$did not alter the peak potential values; however, the peak current of the electrode with $\mathrm{Li}^{+}$decreased to $30 \%$ when it was 


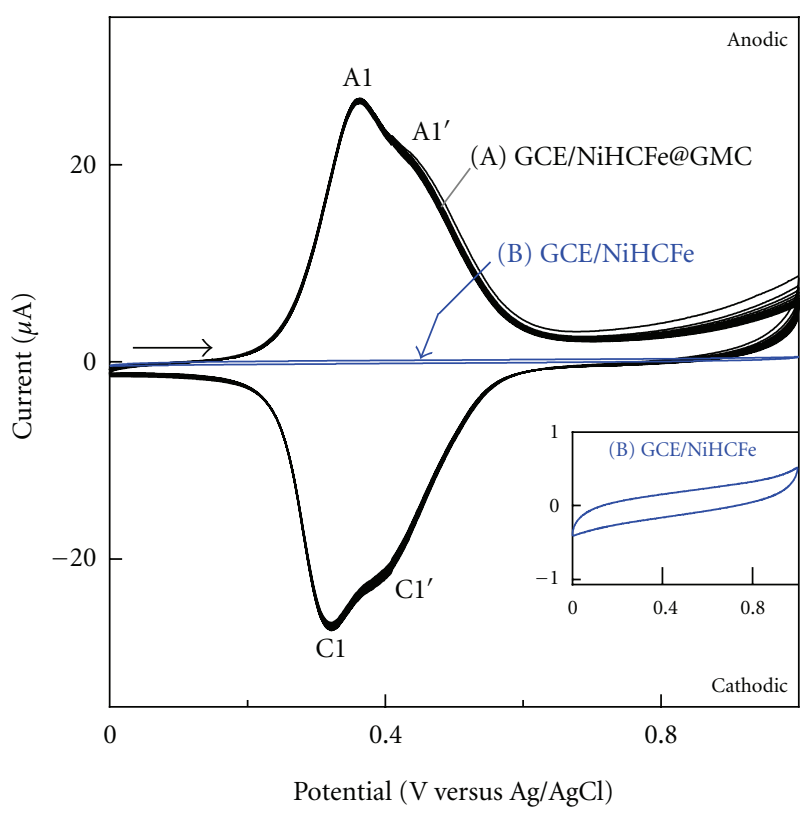

Figure 2: Cyclic voltammograms of GCE/NiHCFe@GMC and $\mathrm{GCE} / \mathrm{NiHCFe}$ in a $\mathrm{pH} 7 \mathrm{PBS}$ at a scan rate of $50 \mathrm{mV} \mathrm{s}^{-1}$.

compared with the presence of $\mathrm{Na}^{+}$. On the other hand, the high ionic radii alkali metals such as $\mathrm{K}^{+}, \mathrm{NH}_{4}^{+}$, and $\mathrm{Ba}^{2+}$ alter both the peak current and peak potential considerably as in Figure 4(a). In our previous study with GCE/NiHCFe@fMWCNT, we have noticed similar kind of observations for both low and high ionic radii alkali metals except with the minor variation in the peak current values between $\mathrm{Li}^{+}$ and $\mathrm{Na}^{+}$ions [27]. Meanwhile, the naked NiHCFe system was reported to be sensitive to all the alkali metals and, thus, resulted in marked alteration in the peak current and potential values [30]. Overall reasons for the alteration in the redox features are due to (i) ionic size of the alkali metal, (ii) ionic size of the solvated layer, (iii) apparent diffusion coefficient $\left(D_{\text {app }}\right)$ of the alkali metal within the film, and (iv) channel size of the NiHCFe cubic crystal. The nanocubic structure of NiHCFe can allow low ionic radii alkali metals $\left(\mathrm{Li}^{+}\right.$and $\left.\mathrm{Na}^{+}\right)$to enter freely into the nanochannel, intercalate, and exhibit coupled chemical electron-transfer reactions. The decrease in the peak current response without altering the $E_{p}$ in presence of $\mathrm{Li}^{+}$(Figure 4(a)) may be due to its $D_{\text {app }}$ and to the huge size of the solvated layer $\mathrm{Li}^{+}$ion [27]. There will be some difficulty in entering the porous channels of NiHCFe@GMC by the high ionic radii metals such as $\mathrm{K}^{+}, \mathrm{NH}_{4}^{+}$, and $\mathrm{Ba}^{2+}$, which may result in marked alteration in the peak current and peak potential values of the NiHCFe (Figure 4(a)). Exact detail of the structure and the mechanism in unknown for us now.

In order to get more detailed information about $\mathrm{Na}^{+}$and $\mathrm{K}^{+}$ion-coupled chemical electron-transfer properties, we have investigated the effect of the alkali metal concentration on the redox behaviors of the GCE/NiHCFe@GMC as in Figure $4(\mathrm{~d})$. For the case of $\mathrm{Na}^{+}$ion, specific alteration in the cathodic peak potential (slope $\sim 52 \mathrm{mV} /$ decade; Nernstian behavior with equal amount of $\mathrm{Na}^{+} / \mathrm{e}^{-}$coupled reaction) and unaltered anodic peak potential behaviors were noticed unlike the totally independent redox behavior with the GCE/NiHCFe@f-MWCNT case [27]. Encapsulation of fraction of $\mathrm{Na}^{+}$ions within the carbon nanotube structure was the reason for the unaltered redox behaviors [27]. Absence of such trapped alkali metal within the GMC matrix might be the reason for the marked alteration in the redox feature of the NiHCFe@GMC unit. In general, anodic and cathodic peaks of $\mathrm{NiHCFe}$ can be referred as exertion and insertion of the alkali metal ions, respectively, on the NiHCFe film [27]. For the $\mathrm{Na}^{+}$case, there might be some difficulty in the insertion of the $\mathrm{Na}^{+}$into the porous structure of the hybrid unit, while the exertion could be relatively faster. As proposed in the earlier section, the NiHCFe sites might be formed within the nanopores of the GMC, which could be least accessible by the $\mathrm{Na}^{+}$ion in this work. Next, the effect of $\mathrm{KCl}$ concentration on the GCE/Ni-NCFe@GMC redox response was also examined by $\mathrm{CV}$ as in Figure 4(c). Plot of $E_{\mathrm{pa}}$ or $E_{\mathrm{pc}}$ versus $\log [\mathrm{KCl}]$ was given in Figure $4(\mathrm{~d})$. Calculated slope $\left(\partial E_{\mathrm{pa}}\right.$ or $\left.\partial E_{\mathrm{pc}} / \partial \log [\mathrm{KCl}]\right)$ values are 37.49 and $87.38 \mathrm{mV} /$ decade, respectively, for the anodic and cathodic redox processes. The values were considerably deviated from the ideal Nernstian value of $59 \mathrm{mV} /$ decade and further suggest participation of nonstoichiometric alkali metal ioncoupled electron-transfer pathways such as $2 \mathrm{~K}^{+} / 3 \mathrm{e}^{-}$(slope $\sim 40 \mathrm{mV} /$ decade) and $3 \mathrm{~K}^{+} / 2 \mathrm{e}^{-}$(slope $\sim 90 \mathrm{mV} /$ decade), respectively, for the anodic and cathodic redox processes. This observation closely resembles with the nonstoichiometric response of the GCE/NiHCFe@f-MWCNT system with slope values of $\sim 40\left(2 \mathrm{~K}^{+} / 3 \mathrm{e}^{-}\right)$, and $120 \mathrm{mV} /$ decade $\left(2 \mathrm{~K}^{+} / 1 \mathrm{e}^{-}\right)$respectively, [27]. Over all the GMC matrix has some unique properties like CNT for the immobilization of NiHCFe units and for characteristic alkali metal ion-coupled electrontransfer behavior.

3.3. Electrocatalytic and Amperometric Sensing of Hydrazine. The electrocatalytic activity of the GCE/NiHCFe@GMC towards oxidation of hydrazine was studied by cyclic voltammetry. Figure 5(a)(A-C) shows comparative $\mathrm{CV}$ responses of GCE/NiHCFe@GMC and GCE/GMC with $1 \mathrm{mM}$ of hydrazine in a pH 7 PBS. As seen in Figure 5(a)(A) the GCE/ NiHCFe@GMC yielded about 20 times enhancement in the oxidation current value and $500 \mathrm{mV}$ reduction in the overpotential over the GCE/GMC (Figure 5(a)(C)) for the hydrazine oxidation reaction, and it is highlighting the efficient catalytic function of the GCE/NiHCFe@GMC in this work. Effect of hydrazine concentration was examined on the working electrode. Upon increasing the hydrazine concentration, a systematic increase in the anodic peak currents was noticed (Figure 5(b)). Plot of baseline corrected anodic peak current $\left(i_{\mathrm{pa}}\right)$ versus concentration of hydrazine was linear up to $1.0 \mathrm{mM}$, after that a plateau in the peak current response was noticed (Figure 5(c)). Calculated current sensitivity value for the hydrazine oxidation by $\mathrm{CV}$ was $15.86 \mu \mathrm{A} / \mathrm{mM}$, which is about 15 times higher in sensitivity than that of the $\mathrm{NiHCFe}$ graphite [28] and sol-gel-derived NiHCFe-modified electrodes [20]. The linear response followed by the plateau observation depicts the electrocatalytic mechanism through the Michaelis-Menten type surface saturation kinetics with 


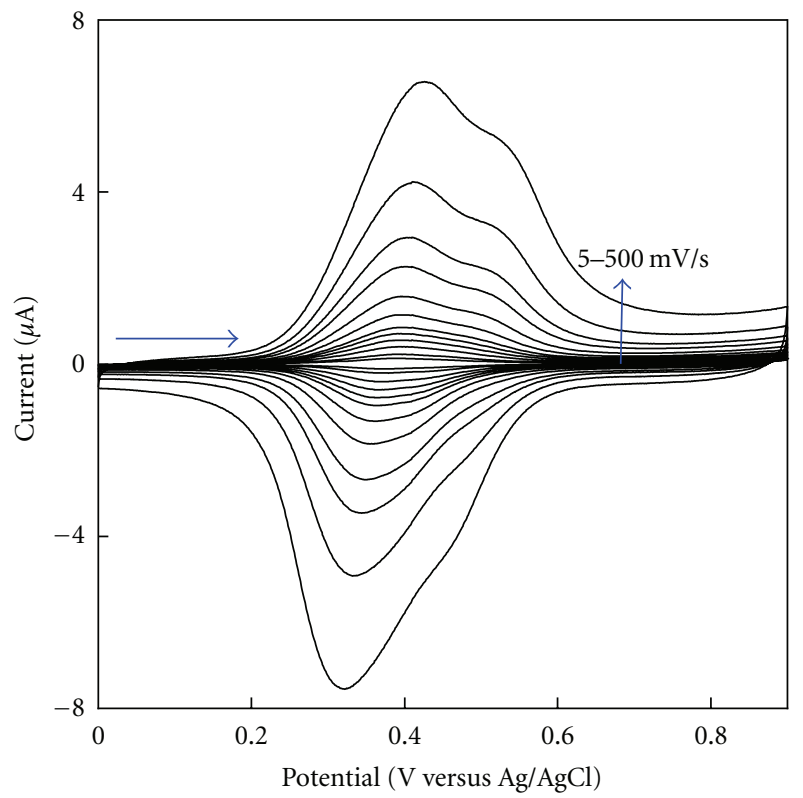

(a)

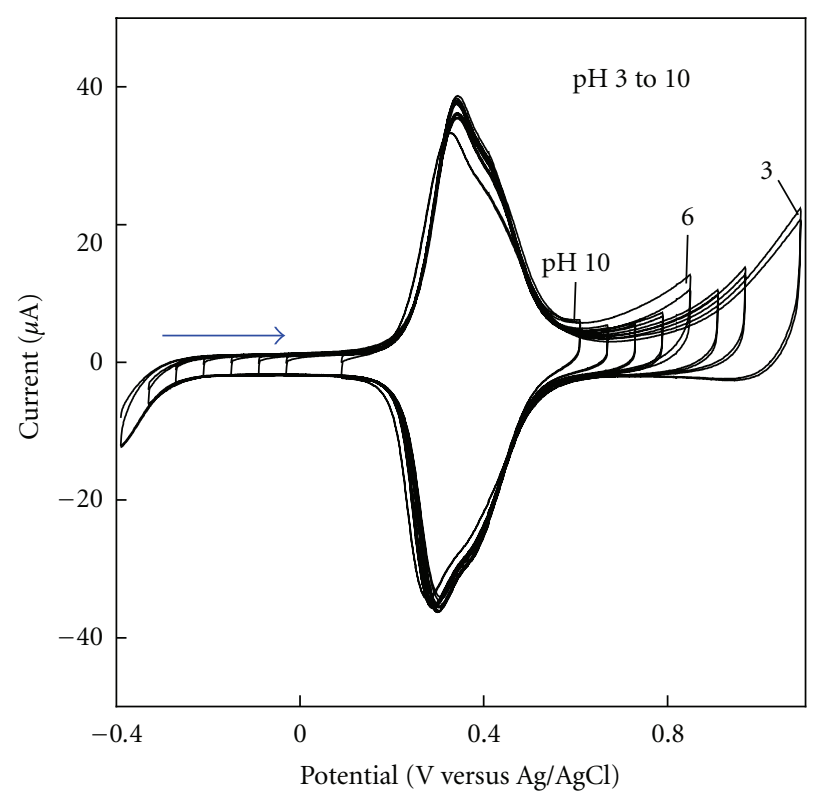

(c)

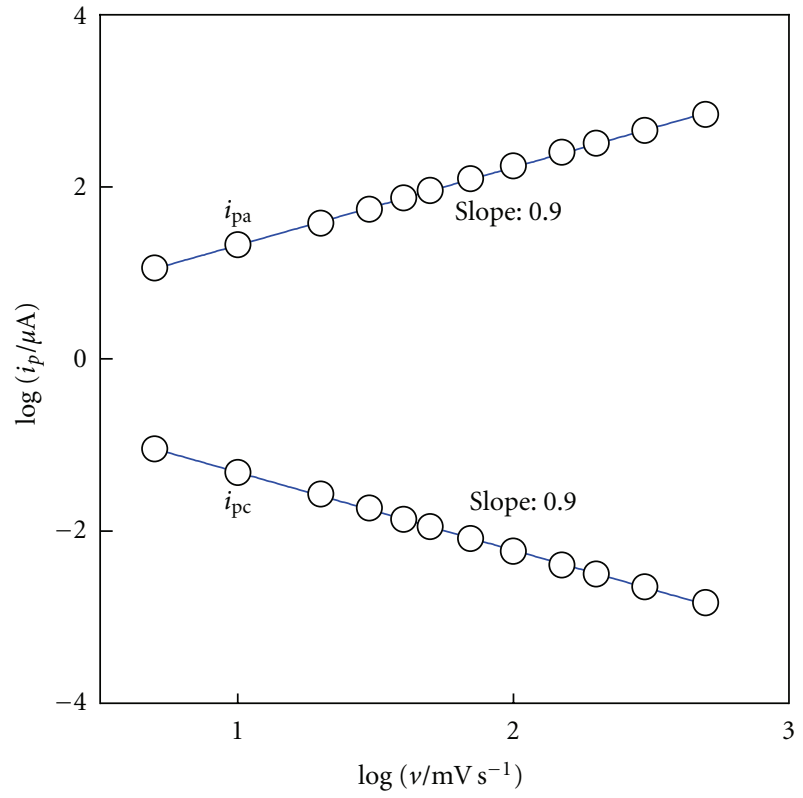

(b)

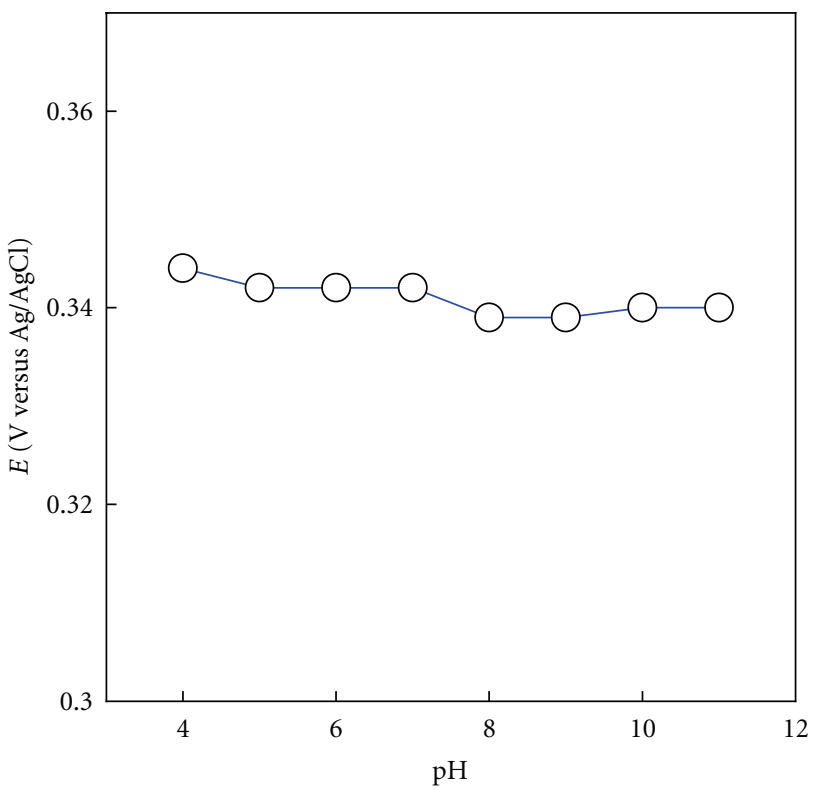

(d)

FIGURE 3: Effect of CV scan rate (a) and pH (c) on GCE/NiHCFe@GMC in pH 7 PBS and its typical plots (b) and (d). Scan rate = 50 mV s s. $^{-1}$

the following type of reaction steps (Scheme 2) [27], where the oxidized form of the NiHCFe, that is, $-\mathrm{Ni}^{\mathrm{II}}-\mathrm{NC}-\mathrm{Fe}^{\mathrm{III}}$ $\mathrm{CN}$-, first react with hydrazine and convert it to $\mathrm{N}_{2}$ and in turn simultaneous formation of reduced form of the NiHCFe, that is, $-\mathrm{Ni}^{\mathrm{II}}-\mathrm{NC}-\mathrm{Fe}^{\mathrm{II}}-\mathrm{CN}-$. This reduced site gets back to the oxidized form by the operating redox potential and subsequently involved in the hydrazine oxidation in a cyclic manner (Scheme 2).

Amperometric $i-t$ detection of hydrazine on GCE/ NiHCFe@GMC at an applied potential of $380 \mathrm{mV}$ versus $\mathrm{Ag} / \mathrm{AgCl}$ was displayed in Figure 6(a)A. Successive spike of $25 \mu \mathrm{M}$ hydrazine results in systematic increase in current signal up to $220 \mu \mathrm{M}$ of hydrazine with a current sensitivity of $7.37 \mathrm{nA} / \mu \mathrm{M}$ (Figure 6(b)). Control amperometric experiments with GCE/Ni@GMC and GCE/GMC showed about three and seven times decrease in the hydrazine current signals as in Figure 6(a)(B) and (C), respectively. Note that the GCE/NiHCFe has failed to show any such amperometric signal for hydrazine in this work (Figure 6(a)(D)), which may be due to absence of catalytic film on the surface as shown in Figure 2(B). Figure 6(b) display typical plots for the amperometric $i-t$ peak currents versus hydrazine concentrations. Calculated relative standard deviation (RSD) for detection of six successive spike of $25 \mu \mathrm{M}$ hydrazine on GCE/ 


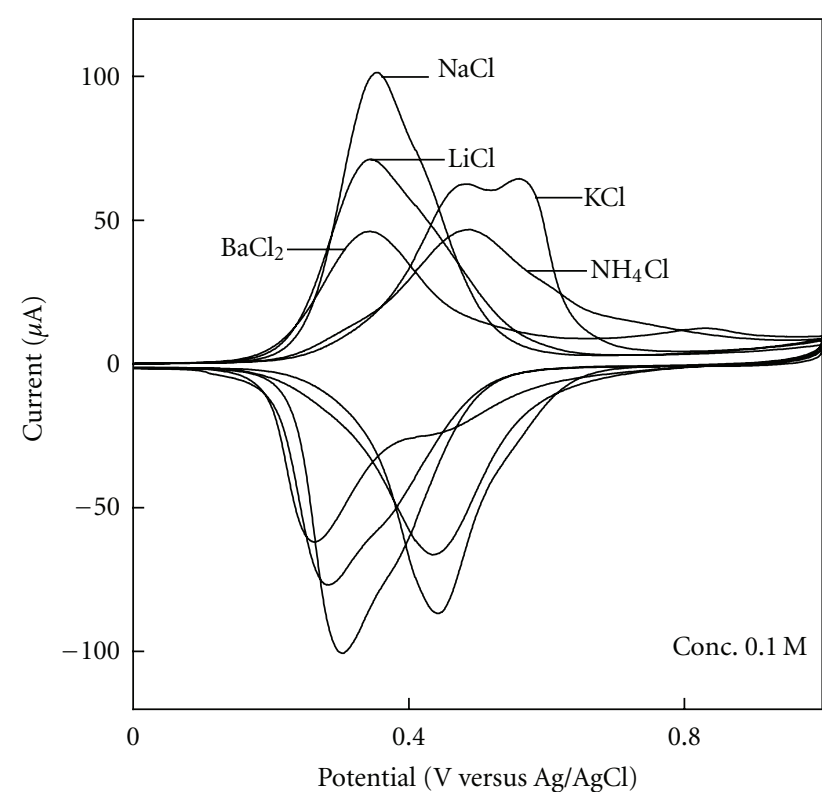

(a)

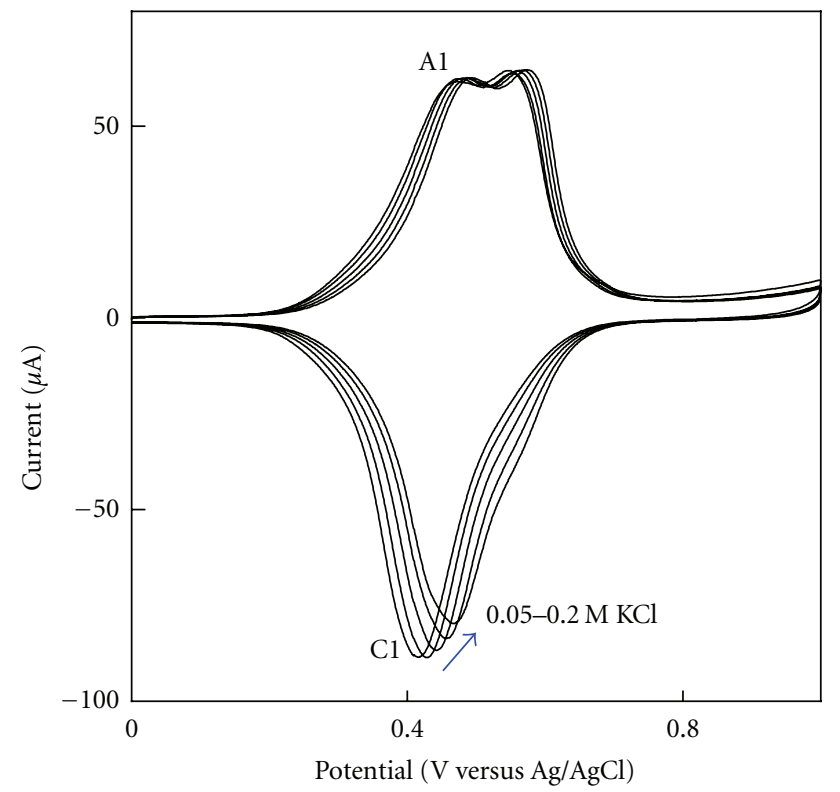

(c)

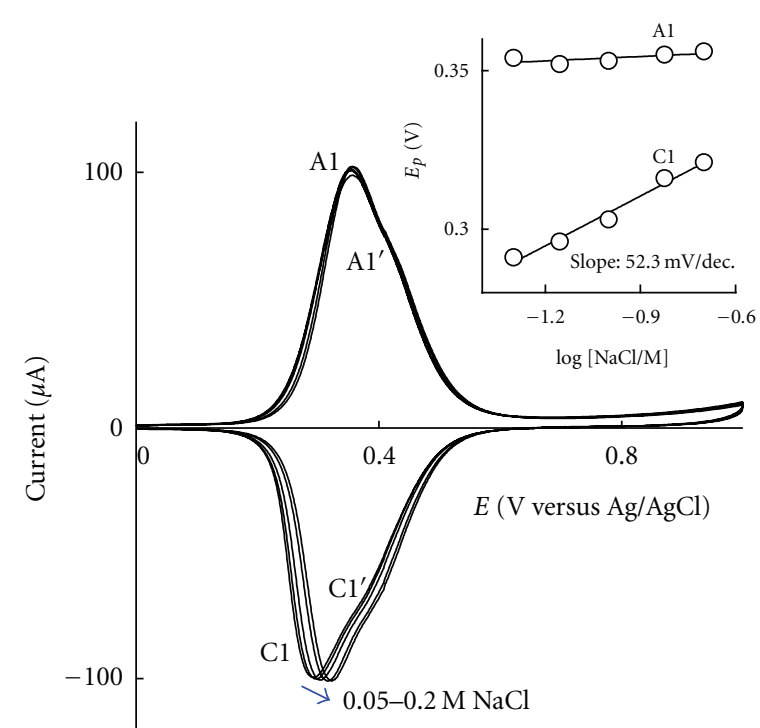

(b)

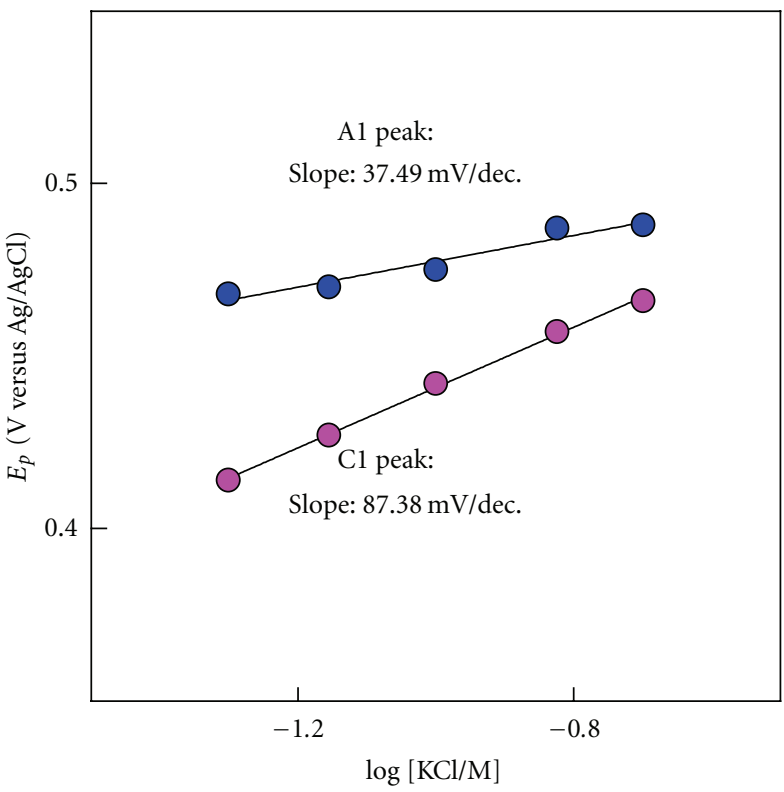

(d)

Figure 4: CV responses of GCE/NiHCFe@GMC at different (a) alkali metal ions and effect of (b) $\mathrm{Na}^{+}$and (c) $\mathrm{K}^{+}$concentrations at a scan rate of $50 \mathrm{mV} / \mathrm{s}$. Figures 3(b) and 3(d) inset are typical $E_{p}$ versus $\log ($ alkali metal ion) plots.

$$
\begin{aligned}
& \underset{\uparrow}{2 \mathrm{NaNi}_{1.5}{ }^{\mathrm{II}}\left[\mathrm{Fe}^{\mathrm{II}}(\mathrm{CN})_{6}\right] @ \mathrm{GMC} \frac{\text { At } 0.38 \mathrm{~V} \text { versus Ag/AgCl}}{\text { Electrochemical step }}} \mathrm{Ni}_{1.5}{ }^{\mathrm{II}}\left[\mathrm{Fe}^{\mathrm{III}}(\mathrm{CN})_{6}\right] @ \mathrm{GMC}+2 \mathrm{e}^{-}+2 \mathrm{Na}^{+} \\
& \mathrm{Ni}_{1.5}\left[\mathrm{Fe}^{\mathrm{III}}(\mathrm{CN})_{6}\right] @ \mathrm{GMC}+2 \mathrm{Na}^{+}+1 / 2 \mathrm{~N}_{2} \mathrm{H}_{4} \stackrel{\text { Chemical step }}{\longrightarrow} 2 \mathrm{NaNi}_{1.5}{ }^{\mathrm{II}}\left[\mathrm{Fe}^{\mathrm{II}}(\mathrm{CN})_{6}\right] @ \mathrm{GMC}+1 / 2 \mathrm{~N}_{2}+2 \mathrm{H}^{+}
\end{aligned}
$$

SCHEME 2: Reaction mechanism for the electrocatalytic oxidation of hydrazine on GCE/NiHCFe@GMC utilizing its A1/C1 redox couple.

NiHCFe@GMC is 1.97\%. Calculated detection limit value $(\mathrm{S} / \mathrm{N}=3)$ is $23.2 \mathrm{nM}$. The detection limit value obtained here is around 26.5 times lesser than previous report with GCE/
NiHCFe@f-MWCNT [27], Ni(II)-Baicalein-MWCNT-Paste electrode [31], NiHCF-NP/CCE [32], and other chemically modified electrodes reported in the literature [11, 28, 33-38] 


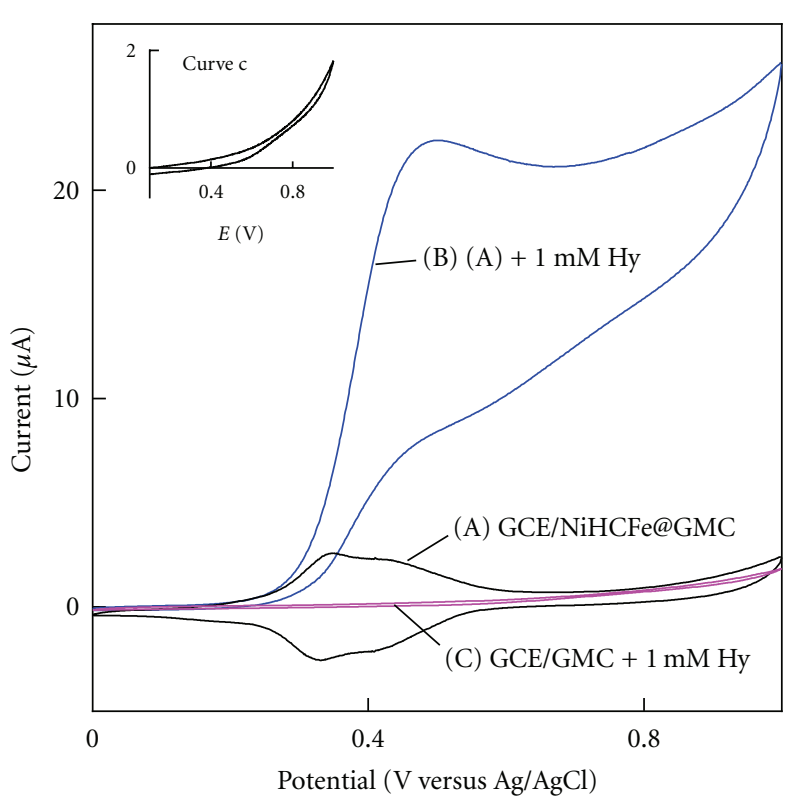

(a)

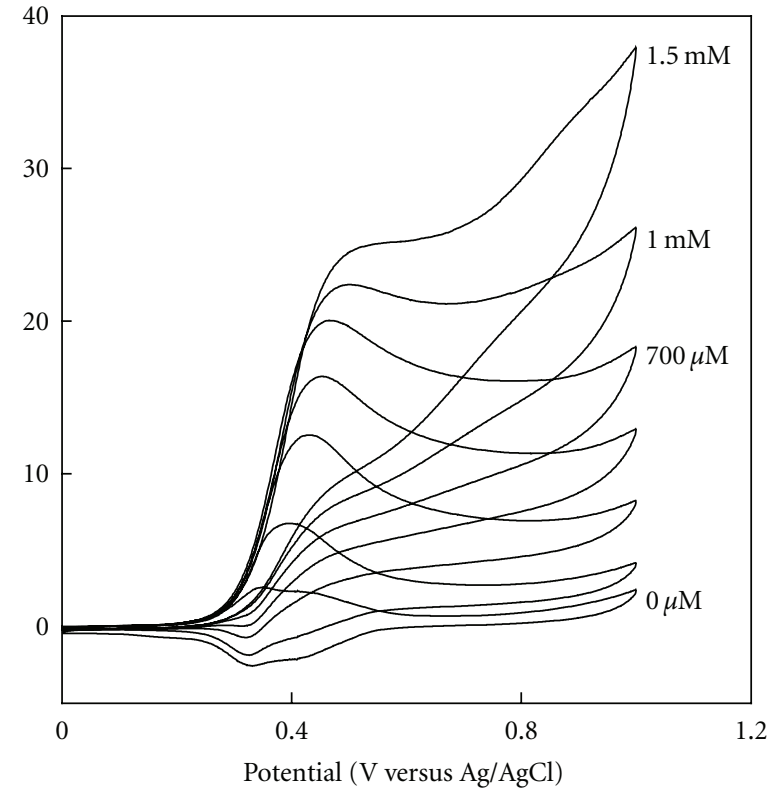

(b)

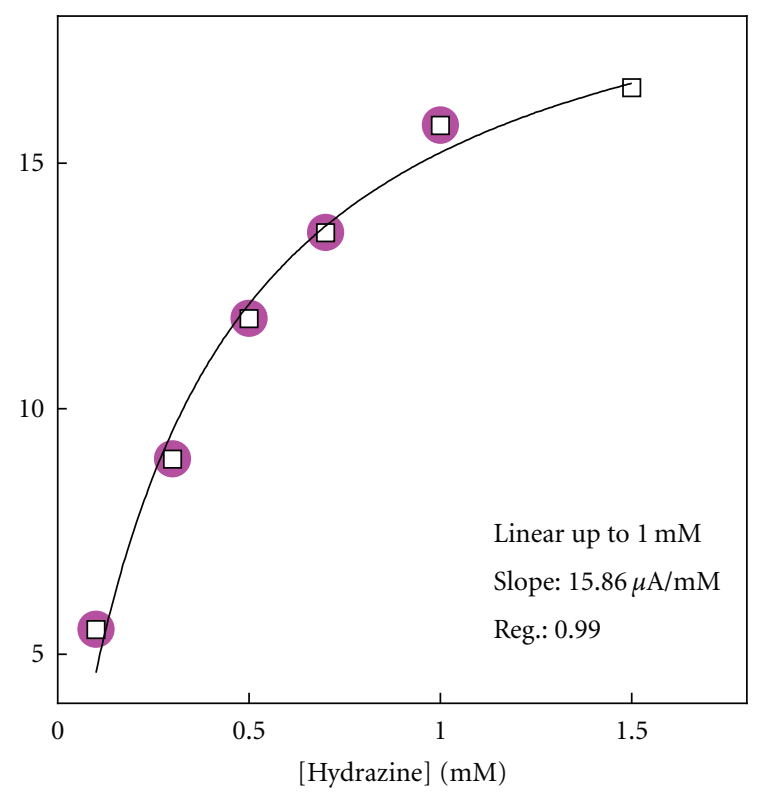

(c)

FIGURE 5: (a) CV responses of GCE/NiHCFe@GMC without and with 1 mM hydrazine (A and B) and GCE/GMC-modified electrode in presence of $1 \mathrm{mM}$ hydrazine (C). (b) CV responses of GCE/NiHCFe@GMC with different concentration of hydrazine. (c) Typical calibration plot.

(Table 1). Observing such a low detection limit value with the GMC-modified electrode might be due to the low background current of the working electrode. Other control hydrazine oxidation experiments using GCE/Ni@GMC, GCE/GMC, and GCE resulted in relatively poor current signal values (Figures 6(a) and 6(b)). Interference effects due to various environmental and biological chemicals were also examined as in Figure 6(c). The GCE/NiHCFe@GMC has remarkable tolerance to the environmental chemicals (nitrite, citric acid, and oxalic acid), which were all often found to be seriously interfered during the hydrazine detection [39]. Meanwhile, feeble interference responses were observed with the biological samples: ascorbic acid, dopamine, and uric acid (Figure 6(d)). In the literature, Nafion was used as an overlayer coating to eliminate those interferences [39]. But no such specific extraneous treatment is required in the present case, which again confirms the promising electroanalytical performance of the present hybrid material. 


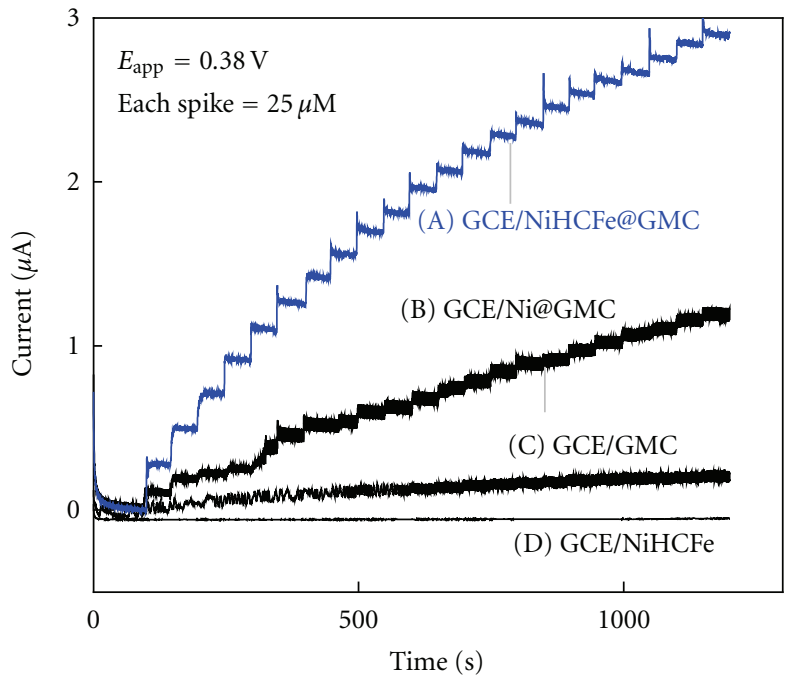

(a)

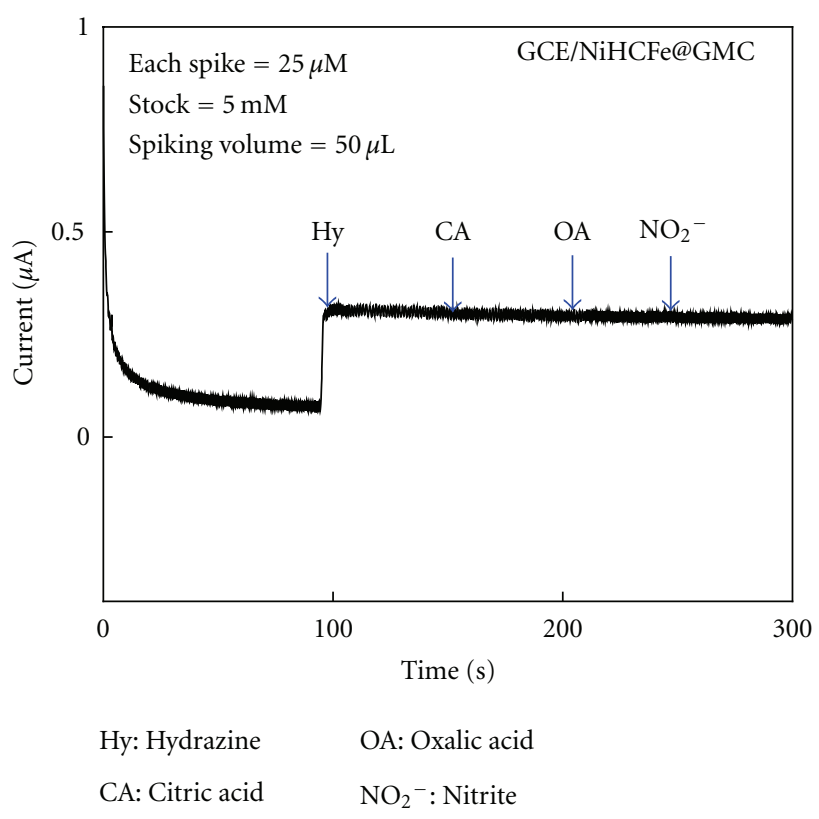

(c)

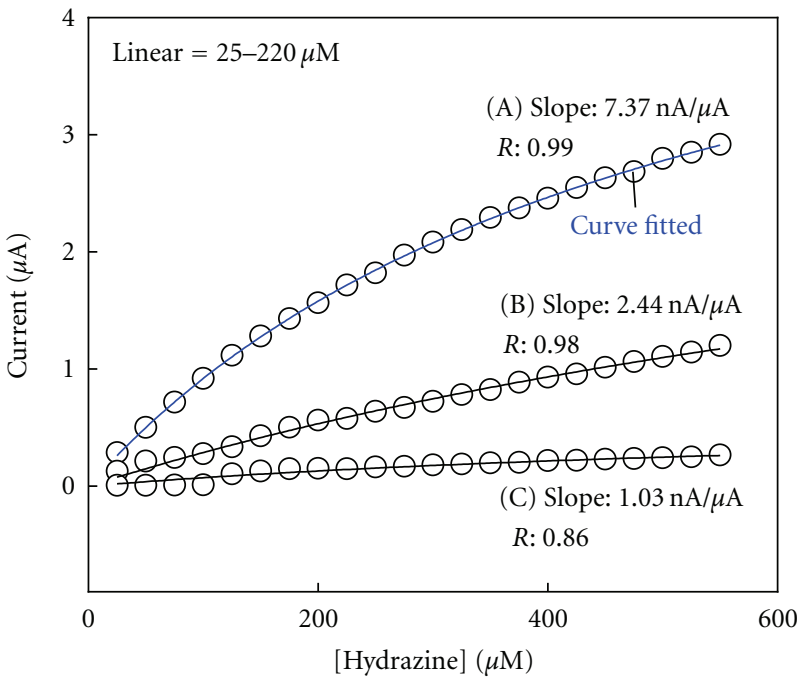

(b)

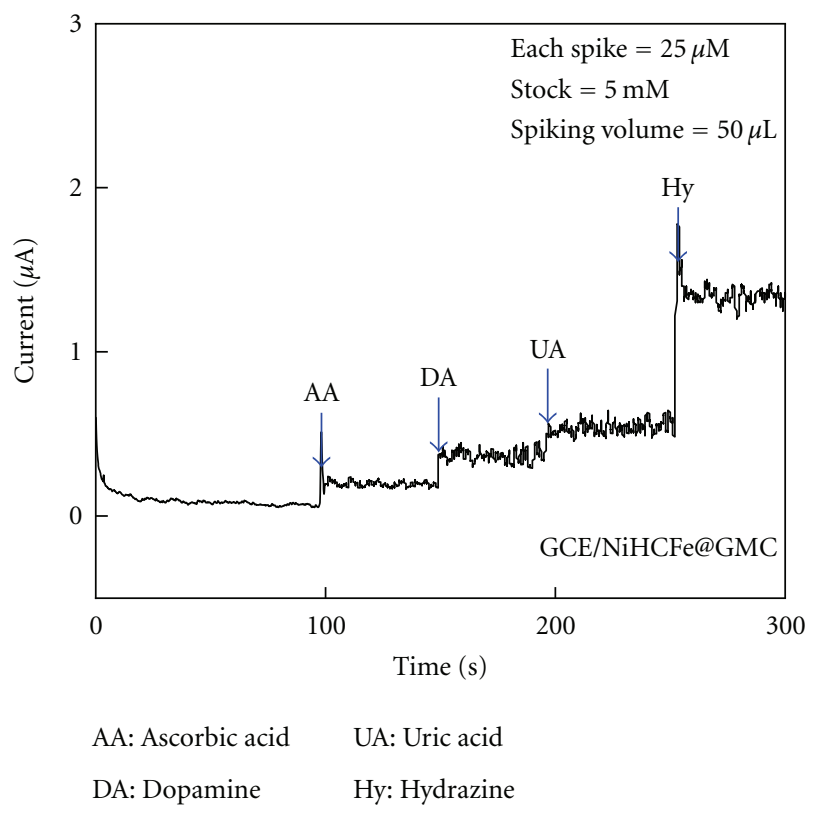

(d)

FIgURE 6: (a) Typical amperometric $i-t$ responses of various chemically modified electrodes for the detection of hydrazine at an applied potential of $0.38 \mathrm{~V}$ versus $\mathrm{Ag} / \mathrm{AgCl}$ in a $\mathrm{pH} 7 \mathrm{PBS}$ and (b) its corresponding plots of current versus hydrazine concentration. (c) and (d) Effect of interferents on GCE/NiHCFe@GMC at an applied potential of $0.38 \mathrm{~V}$.

3.4. Real-Sample Analysis. We have examined the applicability of GCE/NiHCFe@GMC for the determination of hydrazine in cigarette real sample by a standard addition method. Figure 7 shows typical amperometric $i-t$ signal for the analysis of hydrazine present in the cigarette smoke, which is dissolved in pH 7 PBS, using GCE/NiHCFe@GMC as a working electrode. The results are presented in Table 2. Amounts of net hydrazine content were found to be $13.2 \mathrm{ng} /$ cigarette. This hydrazine content value is matching closer with the value of $31.5 \mathrm{ng} /$ cigarette measured by derivatization-based gas chromatographic method previously [8]. The recovery of the spiked sample was found to be around $100 \%$, indicating the appreciable suitability of present working electrode for the real-sample analysis.

Finally, in order to check the stability of the working electrode, CV was performed with the GCE/NiHCFe@GMC before and after the real sample. It is expected that various chemicals present in the real sample may deactivate the working electrode; in such a case marked decrease in the CV response will be expected. Interestingly, no such alteration in 
TABLE 1: Comparison of hydrazine detection limit on various chemically modified electrodes.

\begin{tabular}{|c|c|c|c|c|}
\hline S. No & Modified electrode & $\mathrm{pH}$ & Detection limit $(\mu \mathrm{M})$ & Reference \\
\hline 1 & $\mathrm{Cu}-\mathrm{Pd}$ screen-printed carbon electrodes & 7.4 & 0.27 & {$[11]$} \\
\hline 2 & GCE/NiHCFe@f-MWCNT & 7.0 & 0.62 & {$[27]$} \\
\hline 3 & NiHCFe-graphite electrode & 7.0 & 0.10 & {$[28]$} \\
\hline 4 & Ni(II)-baicalein-MWCNT-paste electrode & 13 & 0.80 & {$[31]$} \\
\hline 5 & NiHCFe-nanoparticle-carbon ceramic electrode & 7.0 & 8.00 & {$[32]$} \\
\hline 6 & Indenedione-MWCNT-carbon ceramic electrode & 7.0 & 0.29 & {$[33]$} \\
\hline 7 & GCE/ZnO-MWCNTs & 7.0 & 0.18 & {$[34]$} \\
\hline 8 & GCE/Mn(II) complex-MWNTs & 8.0 & 0.50 & {$[35]$} \\
\hline 9 & Co(II)complex-MWCNT-carbon paste electrode & 7.0 & 0.10 & {$[36]$} \\
\hline 10 & GCE/CeHCFe-ordered mesoporous carbon & 7.0 & 0.10 & {$[37]$} \\
\hline 11 & Polyethylenedioxy pyrrole/MWCNTs-Pd & 7.4 & 0.04 & {$[38]$} \\
\hline 12 & GCE/NiHCFe@GMC & 7.1 & 0.02 & Present work \\
\hline
\end{tabular}

HCFe: hexacyanoferrate; MWCNT: multiwalled carbon nanotube; f-MWCNT: functionalized-MWCNT; GMC: graphitized mesoporous carbon; GCE: glassy carbon electrode.

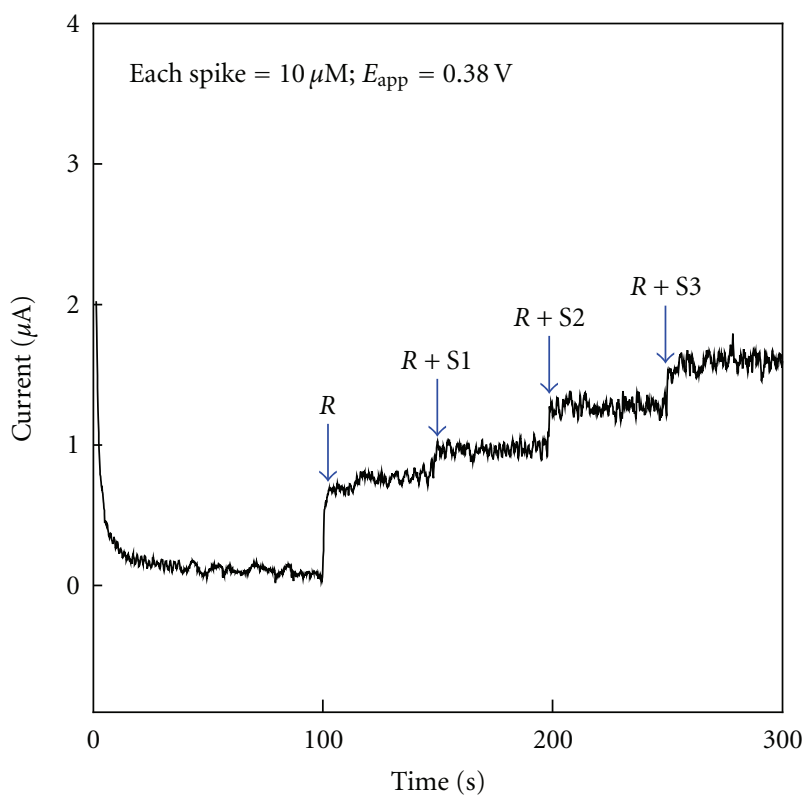

S1-3: Standards

$R:$ Real sample

Figure 7: Amperometric $i$ - $t$ response of GCE/NiHCFe@GMC for the analysis of hydrazine in cigarette smoke dissolved $\mathrm{pH} 7 \mathrm{PBS}$ at an applied potential of $0.38 \mathrm{~V}$ versus $\mathrm{Ag} / \mathrm{AgCl}$.

the peak current and potential values was noticed, further evidencing the good stability and reproducibility of the working electrode even after the real-sample analysis.

\section{Conclusions}

In summary, a low-cost carbon material, GMC, was used as a matrix to immobilize NiHCFe (i.e., GCE/NiHCFe@GMC) and for sensitive and selective detection of hydrazine in a physiological solution. Alkali metal ion interaction with
TABLE 2: Hydrazine content analysis in cigarette smoke real sample using GCE/NiHCFe@GMC by amperometric $i-t$ at an applied potential of $0.38 \mathrm{~V}$ versus $\mathrm{Ag} / \mathrm{AgCl}$.

\begin{tabular}{lcc}
\hline & Cigarette smoke & Parameters \\
\hline 1 & Samples & 4 no's cigarette \\
3 & Linear equation & $y=0.0336 x+0.7397$ \\
4 & Regression & 0.999 \\
5 & Original detect value $(\mu \mathrm{M})$ & 4.087 \\
6 & Spike $(\mu \mathrm{M})$ & 10 \\
7 & Detected after spike $(\mu \mathrm{M})$ & 9.845 \\
8 & Recovery $(\%)$ & 98.45 \\
\hline
\end{tabular}

the NiHCFe@GMC was found to be in the stoichiometric and nonstoichiometric routes. The redox mechanism of the electrode follows surface-confined electron-transfer pathway. The modified hybrid electrode yielded about 20 times higher in the electrocatalytic oxidation of hydrazine than the unmodified electrode. Cyclic voltammetric and amperometric $i-t$ methods of detection of hydrazine showed calibration plots which were linear up to $1 \mathrm{mM}$ and $220 \mu \mathrm{M}$, respectively. Calculated detection limit value for the hydrazine by the amperometric method was $23.2 \mathrm{nM}$, which was about 26.5 times higher than the NiHCFe-functionalized multiwalled carbon nanotube hybrid electrode reported by our group recently. Detection of hydrazine in cigarette smoke sample was successfully demonstrated with appreciable recovery values.

\section{Acknowledgment}

The authors gratefully acknowledge the Department of Science and Technology (DST) Nano Mission Scheme, India, for the financial support. 


\section{References}

[1] L. D. Claxton, R. S. Morin, T. J. Hughes, and J. Lewtas, "A genotoxic assessment of environmental tobacco smoke using bacterial bioassays," Mutation Research, vol. 222, no. 2, pp. 8199, 1989.

[2] H. Zheng and R. C. Shank, "Changes in methyl-sensitive restriction sites of liver DNA from hamsters chronically exposed to hydrazine sulfate," Carcinogenesis, vol. 17, no. 12, pp. 2711-2717, 1996.

[3] U.S. Environmental Protection Agency, Integrated Risk Information System (IRIS) on Hydrazine/Hydrazine Sulphate, National Center for Environmental Assessment, Office of Research and Development, Washington, DC, USA, 1999.

[4] U.S. Environmental Protection Agency, Health and Environmental Effects Profile for Hydrazine and Hydrazine Sulfate, Environmental Criteria and Assessment Office, Office of Health and Environmental Assessment, Office of Reserch and Development, Cincinnati, Ohio, USA, 1984.

[5] S. Budavari, Ed., The Merck Index: An Encyclopedia of Chemicals, Drugs, and Biologicals, Merck \& Co., Rahway, NJ, USA, 11th edition, 1989.

[6] Agency for Toxic Substances and Disease Registry (ATSDR), Toxicological Profile for Hydrazines, Public Health Service, U.S. Department of Health and Human Services, Atlanta, Ga, USA, 1997.

[7] R. Von Burg and T. Stout, "Hydrazine," Journal of Applied Toxicology, vol. 11, no. 6, pp. 447-450, 1991.

[8] Y. Y. Liu, I. Schmeltz, and D. Hoffmann, "Chemical studies on tobacco smoke quantitative analysis of hydrazine in tobacco and cigarette smoke," Analytical Chemistry, vol. 46, no. 7, pp. 885-889, 1974.

[9] S. Plunkett, M. E. Parrish, K. H. Shafer, J. H. Shorter, D. D. Nelson, and M. S. Zahniser, "Hydrazine detection limits in the cigarette smoke matrix using infrared tunable diode laser absorption spectroscopy," Spectrochimica Acta A, vol. 58, no. 11, pp. 2505-2517, 2002.

[10] J. R. Holtzclaw, S. L. Rose, J. R. Wyatt, D. P. Rounbehler, and D. H. Fine, "Simultaneous determination of hydrazine, methylhydrazine, and 1,1-dimethylhydrazine in air by derivatization/ gas chromatography," Analytical Chemistry, vol. 56, no. 14, pp. 2952-2956, 1984.

[11] C. C. Yang, A. S. Kumar, M. C. Kuo, S. H. Chien, and J. M. Zen, "Copper-palladium alloy nanoparticle plated electrodes for the electrocatalytic determination of hydrazine," Analytica Chimica Acta, vol. 554, no. 1-2, pp. 66-73, 2005.

[12] J. W. Sue, A. S. Kumar, H. H. Chung, and J. M. Zen, "Barrel plating rhodium electrode: application to flow injection analysis of hydrazine," Electroanalysis, vol. 17, no. 14, pp. 12451250, 2005.

[13] K. Itaya, I. Uchida, and V. D. Neff, "Electrochemistry of polynuclear transition metal cyanides: prussian blue and its analogues," Accounts of Chemical Research, vol. 19, no. 6, pp. 162$168,1986$.

[14] M. K. Carpenter and R. S. Conell, "Single-film electrochromic device," Journal of the Electrochemical Society, vol. 137, no. 8, pp. 2464-2467, 1990.

[15] S. Longchamp and F. Goubard, " $A B_{5}$-type intermetallic compound as a substrate for nickel hexacyanoferrate modified electrodes," Sensors and Actuators B, vol. 99, no. 2-3, pp. 516524, 2004.

[16] J. Bácskai, K. Martinusz, E. Czirók, G. Inzelt, P. J. Kulesza, and M. A. Malik, "Polynuclear nickel hexacyanoferrates: monitoring of film growth and hydrated counter-cation flux/storage during redox reactions," Journal of Electroanalytical Chemistry, vol. 385, no. 2, pp. 241-248, 1995.

[17] W. A. Steen, S. W. Han, Q. Yu et al., "Structure of cathodically deposited nickel hexacyanoferrate thin films using XRD and EXAFS," Langmuir, vol. 18, no. 20, pp. 7714-7721, 2002.

[18] J. Joseph, H. Gomathi, and G. Prabhakara Rao, "Electrochemical characteristics of thin films of nickel hexacyanoferrate formed on carbon substrates," Electrochimica Acta, vol. 36, no. 10, pp. 1537-1541, 1991

[19] S. Sinha, B. D. Humphrey, and A. B. Bocarsly, "Reaction of nickel electrode surfaces with anionic metal-cyanide complexes: formation of precipitated surfaces," Inorganic Chemistry, vol. 23, no. 2, pp. 203-212, 1984.

[20] A. Salimi and K. Abdi, "Enhancement of the analytical properties and catalytic activity of a nickel hexacyanoferrate modified carbon ceramic electrode prepared by two-step sol-gel technique: application to amperometric detection of hydrazine and hydroxyl amine," Talanta, vol. 63, no. 2, pp. 475-483, 2004.

[21] M. Yang, Y. Yang, F. Qu, Y. Lu, G. Shen, and R. Yu, "Attachment of nickel hexacyanoferrates nanoparticles on carbon nanotubes: preparation, characterization and bioapplication," Analytica Chimica Acta, vol. 571, no. 2, pp. 211-217, 2006.

[22] B. Fang, Y. Feng, G. Wang, C. Zhang, A. Gu, and M. Liu, "A uric acid sensor based on electrodeposition of nickel hexacyanoferrate nanoparticles on an electrode modified with multiwalled carbon nanotubes," Microchimica Acta, vol. 173, pp. 27-32, 2011.

[23] X. Cui, G. Liu, and Y. Lin, "Biosensors based on carbon nanotubes/nickel hexacyanoferrate/glucose oxidase nanocomposites," Journal of Biomedical Nanotechnology, vol. 1, pp. 320327, 2005.

[24] Y. Lin and X. Cui, "Electrosynthesis, characterization, and application of novel hybrid materials based on carbon nanotube-polyaniline-nickel hexacyanoferrate nanocomposites," Journal of Materials Chemistry, vol. 16, no. 6, pp. 585-592, 2006.

[25] Y. Lin and X. Cui, "Novel hybrid materials with high stability for electrically switched ion exchange: carbon nanotube-polyaniline-nickel hexacyanoferrate nanocomposites," Chemical Communications, no. 17, pp. 2226-2228, 2005.

[26] C. C. Wang, M. H. Yang, Y. S. Lu, G. Q. Wu, G. L. Shen, and R. Q. Yu, "Glucose biosensor based on the synergy between carbon nanotubes and nickel hexacyanoferrate nanoparticles," Huaxue Xuebao, vol. 64, pp. 1355-1360, 2006.

[27] A. S. Kumar, P. Barathi, and K. Chandrasekara Pillai, "In situ precipitation of Nickel-hexacyanoferrate within multi-walled carbon nanotube modified electrode and its selective hydrazine electrocatalysis in physiological $\mathrm{pH}$," Journal of Electroanalytical Chemistry, vol. 654, no. 1-2, pp. 85-95, 2011.

[28] S. J. Richard Prabakar and S. Sriman Narayanan, "Amperometric determination of hydrazine using a surface modified nickel hexacyanoferrate graphite electrode fabricated following a new approach," Journal of Electroanalytical Chemistry, vol. 617, no. 2, pp. 111-120, 2008.

[29] H. Razmi and K. Heidari, "Electroless immobilization and electrochemical characteristics of nickel hexacyanoruthenate film at an aluminum substrate," Electrochimica Acta, vol. 51, no. 7, pp. 1293-1303, 2006.

[30] M. A. Malik, P. J. Kulesza, R. Marassi, F. Nobili, K. Miecznikowski, and S. Zamponic, "Countercation intercalation and kinetics of charge transport during redox reactions of nickel hexacyanoferrate," Electrochimica Acta, vol. 49, no. 25, pp. 4253-4258, 2004. 
[31] L. Zheng and J. F. Song, "Ni(II)-baicalein complex modified multi-wall carbon nanotube paste electrode toward electrocatalytic oxidation of hydrazine," Talanta, vol. 79, no. 2, pp. 319-326, 2009.

[32] A. Abbaspour, A. Khajehzadeh, and A. Ghaffarinejad, "Electrocatalytic oxidation and determination of hydrazine on nickel hexacyanoferrate nanoparticles-modified carbon ceramic electrode," Journal of Electroanalytical Chemistry, vol. 631, no. 1-2, pp. 52-57, 2009.

[33] H. R. Zare, N. Nasirizadeh, F. Chatraei, and S. Makarem, "Electrochemical behavior of an indenedione derivative electrodeposited on a renewable sol-gel derived carbon ceramic electrode modified with multi-wall carbon nanotubes: application for electrocatalytic determination of hydrazine," Electrochimica Acta, vol. 54, no. 10, pp. 2828-2836, 2009.

[34] B. Fang, C. Zhang, W. Zhang, and G. Wang, "A novel hydrazine electrochemical sensor based on a carbon nanotube-wired $\mathrm{ZnO}$ nanoflower-modified electrode," Electrochimica Acta, vol. 55, no. 1, pp. 178-182, 2009.

[35] M. A. Kamyabi, O. Narimani, and H. H. Monfared, "Electrocatalytic oxidation of hydrazine using glassy carbon electrode modified with carbon nanotube and terpyridine manganese (II) complex," Journal of Electroanalytical Chemistry, vol. 644, no. 1, pp. 67-73, 2010.

[36] A. Benvidi, P. Kakoolaki, H. R. Zare, and R. Vafazadeh, "Electrocatalytic oxidation of hydrazine at a $\mathrm{Co}$ (II) complex multiwall carbon nanotube modified carbon paste electrode," Electrochimica Acta, vol. 56, no. 5, pp. 2045-2050, 2011.

[37] H. Yang, B. Lu, L. Guo, and B. Qi, "Cerium hexacyanoferrate/ordered mesoporous carbon electrode and its application in electrochemical determination of hydrous hydrazine," Journal of Electroanalytical Chemistry, vol. 650, no. 2, pp. 171-175, 2011.

[38] S. K. Kim, Y. N. Jeong, M. S. Ahmed, J. M. You, H. C. Choi, and S. Jeon, "Electrocatalytic determination of hydrazine by a glassy carbon electrode modified with PEDOP/MWCNTsPd nanoparticles," Sensors and Actuators B, vol. 153, no. 1, pp. 246-251, 2011.

[39] J. M. Zen and A. S. Kumar, "A mimicking enzyme analogue for chemical sensors," Accounts of Chemical Research, vol. 34, no. 10, pp. 772-780, 2001 


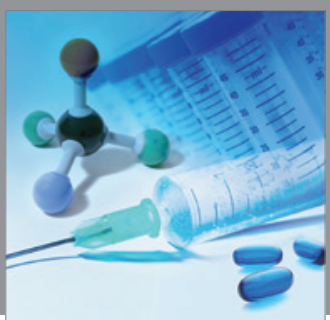

International Journal of

Medicinal Chemistry

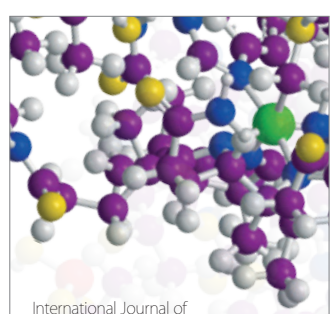

Carbohydrate Chemistry

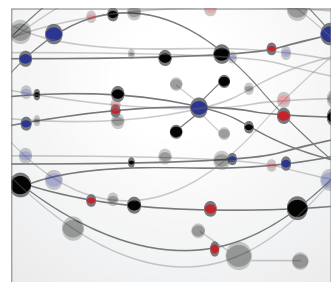

The Scientific World Journal
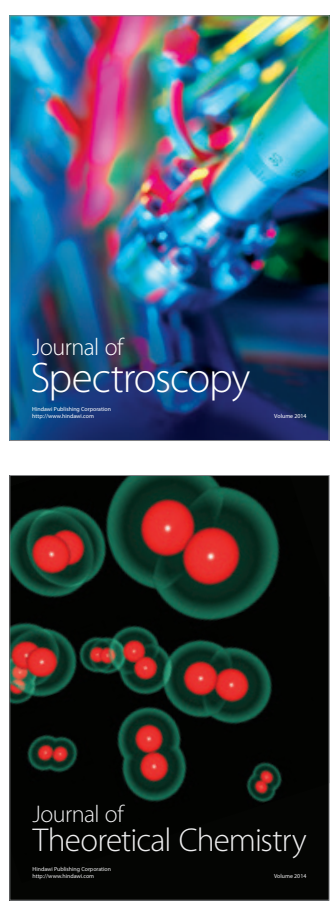
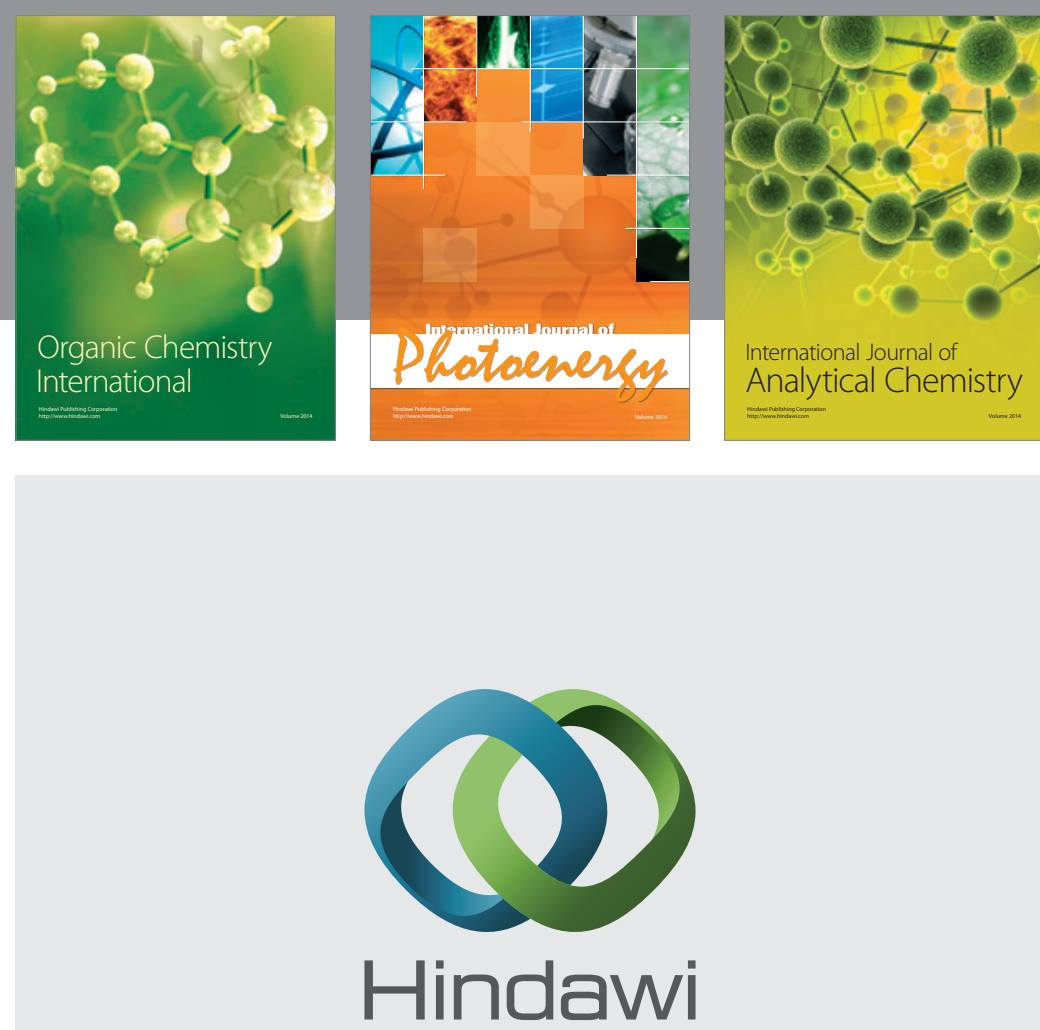

Submit your manuscripts at

http://www.hindawi.com
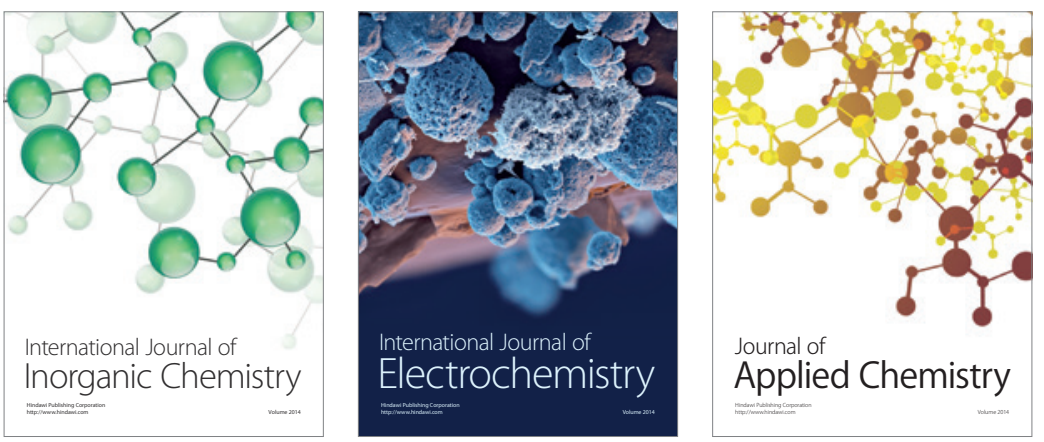

Journal of

Applied Chemistry
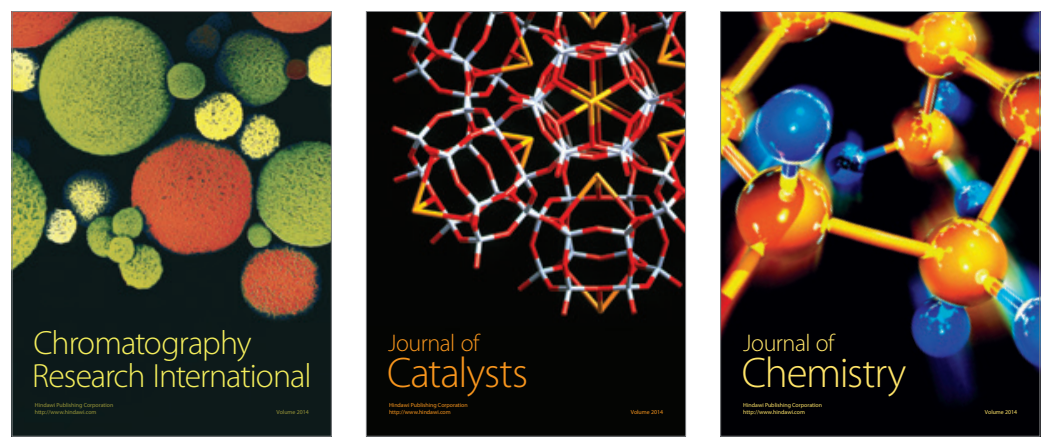
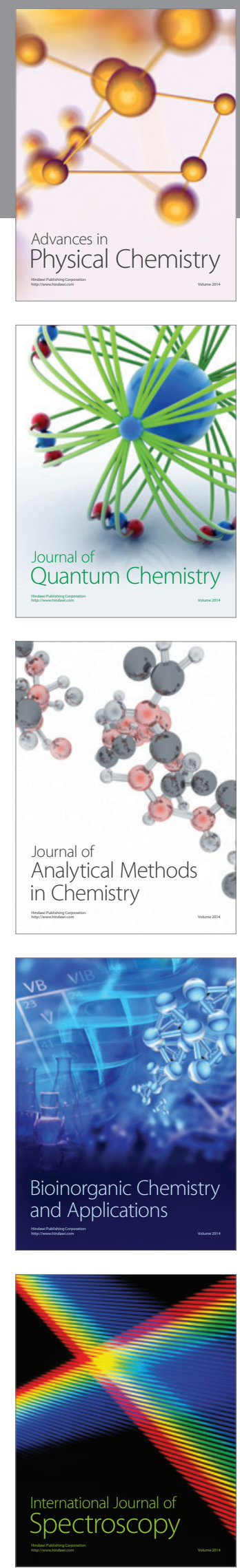